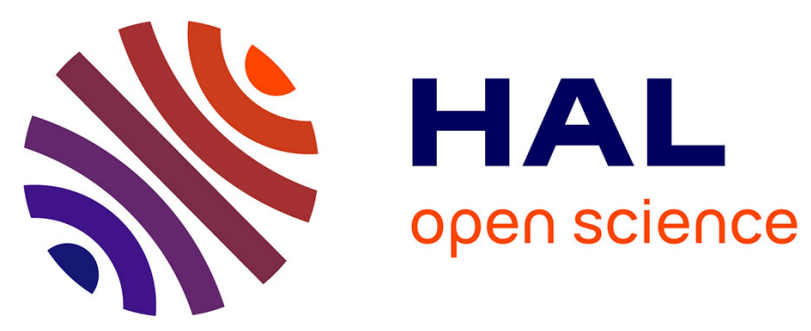

\title{
Male Gammarus roeseli provide smaller ejaculates to females infected with vertically transmitted microsporidian parasites.
}

Christelle Couchoux, François-Xavier Dechaume-Moncharmont, Thierry Rigaud, Loïc Bollache

\section{To cite this version:}

Christelle Couchoux, François-Xavier Dechaume-Moncharmont, Thierry Rigaud, Loïc Bollache. Male Gammarus roeseli provide smaller ejaculates to females infected with vertically transmitted microsporidian parasites.. Animal Behaviour, 2018, 137, pp.179-185. 10.1016/j.anbehav.2018.01.008 . hal-01711966

\section{HAL Id: hal-01711966 \\ https://hal.science/hal-01711966}

Submitted on 7 Jan 2022

HAL is a multi-disciplinary open access archive for the deposit and dissemination of scientific research documents, whether they are published or not. The documents may come from teaching and research institutions in France or abroad, or from public or private research centers.
L'archive ouverte pluridisciplinaire HAL, est destinée au dépôt et à la diffusion de documents scientifiques de niveau recherche, publiés ou non, émanant des établissements d'enseignement et de recherche français ou étrangers, des laboratoires publics ou privés. 
1 Male Gammarus roeseli provide smaller ejaculates to females infected

2 with vertically transmitted microsporidian parasites

3

4 COUCHOUX Christelle ${ }^{a, b}$ DECHAUME-MONCHARMONT François-Xaviera,

5 RIGAUD Thierry ${ }^{a} \&$ BOLLACHE Loic ${ }^{* c}$

6

7

8 aLaboratoire Biogéosciences, UMR CNRS 6282, Université Bourgogne Franche-

9 Comté, Dijon, France

$10{ }^{b}$ Centre for Ecology and Conservation, College of Life and Environmental Sciences,

11 University of Exeter, Cornwall, UK (current address)

12 'Laboratoire Chrono-Environnement, UMR CNRS 6249, Université Bourgogne

13 Franche-Comté, Besançon, France

14

15 *Author for correspondence: Loic Bollache, Laboratoire Chrono-Environnement, UMR 16 CNRS 6249, Université Bourgogne Franche-Comté, La Bouloie, UFR des Sciences 17 et Techniques, 16 route de Gray, 25030 Besançon cedex. Loic.Bollache@u18 bourgogne.fr 


\section{Abstract}

22 The effects of parasites on the reproduction of their hosts are widespread, but studies 23 investigating the effect of female parasitic status on sperm allocation in the males, a 24 form of post-copulatory mate choice, remain scarce. Because males are often sperm25 limited, strategic sperm investment, in which females of low reproductive value 26 receive fewer sperm, is predicted to occur so as to maximise long-term male reproductive success. In this study based on pairs collected in natura, we investigated how Gammarus roeseli (Crustacea: Amphipoda) males allocated sperm when paired with females infected with the vertically-transmitted, sex ratio distorting, microsporidian parasites, Nosema granulosis or Dictyocoela sp. Since infected

31 females had similar fecundity than uninfected ones, and offspring of females infected with $N$. granulosis showed a higher survival rate, we predicted equivalent or even larger sperm investment from males paired with infected females. Contrary to our predictions, males paired with infected females had lower sperm reserves prior to ejaculation and provided smaller size ejaculates compared to those paired with uninfected females. This pattern suggests either a strategic sperm investment as a function of the female parasitic status, or that males in good condition managed to pair with uninfected females with a higher probability than those in bad condition.

Keywords: mate choice, mate guarding, sperm investment, Nosema granulosis,

Dictyocoela 
44 The effects of parasites on the reproduction of their hosts are widespread and diverse (Poulin 2007). In particular, the seminal paper by Hamilton \& Zuk (1982) drew attention to the fact that parasite infections could be a major evolutionary force driving host's sexual selection and sexual behaviour. Among this broad area of research, studies on effects of parasites on male sperm production and investment are scarce. Most of them have investigated the direct effect of the parasitic status of the male on its sperm production, with evidence of either negative effects (e.g. Yan \& Stevens 1995; Galipaud, Dechaume-Moncharmont, Oughadou \& Bollache, 2011) or positive effects (reflecting an increased investment to compensate negative effects of parasitism on other life-history traits) (Figenschou et al. 2013; Haeussler, Schmera \& Baur, 2014). Only a few studies have investigated the effect of female parasitic status on sperm allocation in the male (Edward \& Chapman 2011). Due to intense malemale competition and because males are sperm-limited, strategic sperm investment is predicted to occur at each mating event to maximise the overall fertilisation success (Wedell, Gage \& Parker, 2002; Jarrige, Riemann, Goubault \& Schmoll, 2015; but see Arundell, Wedell \& Dunn, 2014). In particular, males may provide females of low reproductive value with fewer sperm (Reinhold, Kurtz \& Engqvist, 2002). Parasitic infections decrease host fitness, and are therefore a source of variation in the quality of potential mates. Female parasitic status could therefore promote strategic sperm allocation by males, with greater allocation of sperm to high quality (uninfected) females, and prudent sperm allocation to females of low quality. This is especially true in the eventuality of numerous potential future mates, because these future mates could be of higher quality (Reinhold, Kurtz \& Engqvist, 2002, Edward \& Chapman 2011). 
When parasites are vertically transmitted (from mother to offspring via the eggs), they are under strong evolutionary pressure to distort the primary sex ratio of their hosts, through male killing or feminisation (Bandi, Dunn, Hurst \& Rigaud 2001). By reversing genetic males into phenotypic females, feminising microbes increase their transmission efficiency by increasing the frequency of the transmitting sex (females). For instance, feminisation is induced by the bacterium Wolbachia (Bouchon, Rigaud \& Juchault 1998; Kageyama, Nishimura, Hoshizaki \& Ishikawa 2002) and by parasites from the eukaryotic phylum Microspora (Terry et al. 2004). Because they often result in female-biased populations, parasitic sex ratio distorters are a selective force in the evolution of mating behaviour (Charlat, Hurst \& Mercot 2003) and mate choice (Jiggins, Hurst \& Majerus 2000; Moreau, Bertin, Caubet \& Rigaud 2001). In the crustacean isopod Armadillidium vulgare, not only males prefer to mate with uninfected (real) females vs. infected ones (genetic males reversed by the feminising bacterium Wolbachia) (Moreau, Bertin, Caubet \& Rigaud 2001), but they also allocate smaller size ejaculates to infected females, resulting in a decrease in fertility (Rigaud \& Moreau 2004). Because on average infected and uninfected females had the same fecundity, this lesser allocation to infected females has been attributed to the abnormal (incomplete) behaviour expressed by the reversed-females during courtship and copulation (Moreau \& Rigaud 2001, Rigaud \& Moreau 2004). The crustacean amphipod Gammarus duebeni has been found to be infected with sex ratio distorting parasites: the microsporidian parasites Nosema granulosis and Dictyocoela duebenum (Terry, Smith, \& Dunn 1998; Ironside \& Alexander 2015).

90 Dunn et al. (2006) showed that males provide smaller size ejaculates to females 91 infected with $N$. granulosis, relative to uninfected females. As infected females 
ejaculate size has been interpreted as a strategic sperm allocation; the males saving most of their sperm reserve for females of high quality. Assessment of female quality could be favoured in amphipods because of a long-lasting phase of precopulatory mate guarding involving close proximity with the female for up to three weeks (Galipaud, Bollache, Oughadou \& Dechaume-Moncharmont 2015).

In most freshwater crustaceans, including Gammarus roeseli, reproduction is characterized by a precopulatory mate guarding phase during which males guard a potential mate by carrying a female beneath their ventral surface for several days before copulation. This behaviour is tightly linked to females' moulting cycle. While males are considered available for mating during most of their moult cycle (Sutcliffe 1992), females are only receptive to copulation shortly after moulting and just for a few hours. After copulation, they begin a new moulting cycle, which can last from several days up to several weeks depending on the species (Jormalainen 1998). Gammarus roeseli belong to the group of multivoltine iteroparous annuals (lifetime 12-24 months) and females moult six to eight times, thus potentially producing six to eight broods (Pöckl 1993).

Because females' moulting cycles, and hence receptivity to copulation, are asynchronous, the operational sex ratio is predicted to be strongly biased towards males. Precopulatory mate guarding behaviour is thought to have evolved as a male competitive strategy in response to the brief period of female receptivity (Parker 1974; Grafen \& Ridley 1983). Males are in competition for access to females, in particular to 'high-quality' females. From a male perspective, the female's quality as a mate strongly depends on fecundity, and the male pairing decision to engage mate guarding is known to be negatively influenced by female parasitism status (Bollache et al. 2002). 
Most populations of the amphipod $G$. roeseli are infected with microsporidian

119 parasites in the rivers of Western Europe (Haine et al. 2004; Gismondi, Rigaud,

120 Beisel \& Cossu-Leguille 2012; Grabner et al. 2015). Three of these parasite species

121 (Nosema granulosis, Dictyocoela muelleri and Dictyocoela sp. (roeselum)) have been

122 shown to be vertically-transmitted, and associated with female-biased sex ratios

123 (Haine et al. 2004; Haine, Motreuil \& Rigaud 2007). In contrast with the parasites

124 infecting $G$. duebeni, the microsporidia in $G$. roeseli are not associated with a

125 decrease in fecundity (Haine et al. 2004) and the microsporidia of the genus

126 Dictyocoela had only a slight impact on the host's physiology in absence of other

127 stresses (Gismondi, Rigaud, Beisel \& Cossu-Leguille 2012). Nosema granulosis even

128 provides its hosts an advantage in survival relative to uninfected females (Haine,

129 Motreuil \& Rigaud 2007). Here, we tested the hypothesis of an effect of females'

130 parasitic status on males' reproductive strategy. Male gammarids are sperm-limited,

131 and long lasting precopulatory mate guarding leaves opportunities for an accurate

132 assessment of female quality. We thus predicted that $G$. roeseli males allocate more

133 sperm to females infected with $N$. granulosis, but show no difference in sperm

134 allocation between uninfected females and females infected with parasites of the 135 genus Dictyocoela.

\section{Methods}

139 Ethical note

140 This work followed the $A B S / A S A B$ guidelines for the treatment of animals in

141 behavioural research. Information about individuals' origin, and housing conditions

142 are described below. Transport between sampling site and laboratory, housing 
143 conditions, handling, as well as experimental monitoring, have been conducted in order to reduce stress and maximise animals' welfare. We complied with the French regulations for experiments on invertebrates.

Animal collection, maintenance and general procedures

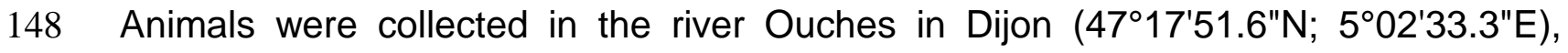

149 using kick sampling method with a hand net. Gammarids exhibit a precopulatory

150 mate guarding behaviour (they grasp females several days before egg laying) in

151 order to ensure the reproduction of the future batch of eggs (Sutcliffe 1992).

152 Immediately upon sampling, couples were isolated in individual plastic tubes, and

153 were brought back to the laboratory. Each pair was then housed individually under a

154 12:12 light:dark cycle regime, at $15^{\circ} \mathrm{C}( \pm 1)$, in boxes $(h=7 \mathrm{~cm} ; \varnothing=9 \mathrm{~cm})$ filled with

155 water from the river mixed with tap water previously dechlorinated, UV-treated and 156 oxygenated.

157 Couples were then randomly assigned to one of the two following experiments. The

158 first experiment aimed at understanding the effect of female infection status on male

159 ejaculate size. Fertilisation is semi-external in gammarids: after the female has laid

160 eggs, the male deposits sperm in her ventral incubating 'pouch'. As water can flow in

161 the pouch, it is impossible to collect male ejaculates. Sperm investment is therefore

162 estimated by comparing sperm reserves in testes between two treatment groups;

163 males before copulation (during mate guarding), and males after a copulation event

164 (not holding the female anymore, the female having released eggs) (Dunn et al.

165 2006; Lemaître, Rigaud, Cornet \& Bollache 2009). Males were anaesthetised using

166 carbonised water and dissected to estimate their sperm reserves. In the first group ( $\mathrm{n}$

$167=64$ ), males were dissected before insemination (within two days after their arrival in 
168 the lab). In the second group $(n=61)$, sperm remaining in testes were counted after

169 copulation, on the same day. Females were also anaesthetised and dissected. The 170 eggs were flushed out from the incubating pouch and counted. To assess the

171 female's infection status by microsporidia, the gonads were dissected and stored in 172 pure ethanol until molecular analysis. Prior to dissection, the size of each animal was

173 estimated by measuring the height of the fourth coxal plate, using a Nikon SMZ 1500

174 stereoscopic microscope and the Lucia G 4.81 software.

175 The second experiment aimed at assessing sperm replenishment kinetics after

176 copulation. Sperm were therefore counted in males 2, 4, 8 and 12 days after the 177 insemination ( $\mathrm{n}=21,22,20,20$, respectively). The second group of the first 178 experiment served as reference for sperm reserves just after insemination (0 days 179 after insemination, $\mathrm{n}=64)$. At the end of the experiments, all non-dissected 180 individuals were released back into the river they came from.

\section{Sperm counting}

183 Sperm was counted as described in Lemaître, Rigaud, Cornet \& Bollache (2009).

184 One testis per individual was isolated in a watch glass, in $1000 \mu \mathrm{L}$ of demineralised 185 water. After isolation, the gonad was dissected under a binocular microscope. The 186 fragments of gonad were submitted to $10 \mathrm{~s}$ of ultra-wave treatment to separate the 187 membranes from the sperm (Ultra-waves tank, Branson 2200 Branson Cleaning 188 Equipment Company, Shelton, Co, U.S.A.) and homogenised. For each male, four 10

$189 \mu \mathrm{L}$ samples were placed on a slide and dried for $10 \mathrm{~min}$ at $37^{\circ} \mathrm{C}$. All sperm in each 190 drop were counted under an optic microscope Nikon Eclipse E600 (magnification 191 x100). Statistical analyses were carried out using the sum of the number sperms in 
192 the four drops, since the counting appeared repeatable between drops $(R=0.964$,

$19395 \% \mathrm{Cl}=[0.953 ; 0.975])$.

194

195

196

197

198

199

Infection status

Microsporidia detection and identification were performed using a PCR-RFLP method, following Haine et al. (2004). After DNA extraction from the female's gonads, a PCR test was conducted with the primers V1f and 530r, amplifying a fragment of the microsporidian $16 \mathrm{~S}$ ribosomal gene only in case of parasite infection (Haine et al. 2004). The size of the amplification product allowed to discriminate between Nosema granulosis and Dictyocoela parasites, and the use of restriction enzymes Vspl and Bst1107I (MBI fermentas) allowed to discriminate between the $D$. muelleri and the $D$. sp. (roeselum) sequences, respectively (Haine et al. 2004). Vspl enzyme revealed only females infected with Dictyocoela sp. (roeselum) in this study, hereafter referred as "Dictyocoela". Males were not tested for the presence of parasites since prevalence in males in this population is close to zero (Haine et al. 2004).

\section{Statistical analyses}

Female fecundity was analysed with a general linear model including the following factors: female size, insemination status of males (before or after insemination), and infection status of females (uninfected, infected with $N$. granulosis, infected with Dictyocoela) and their two-order interactions. The repeatability of sperm count was estimated using 'rptR' packages (Stoffel, Nakagawa \& Schielzeth 2017). Sperm reserves in males were analysed using a general linear model including the following factors: male size, insemination status (before or after insemination), and infection status of females (uninfected, infected with $N$. granulosis, infected with Dictyocoela) 
and their two-order interactions. Sperm replenishment data were analysed using a

218 general linear model including the following factors: male size, day after insemination

219 (treated as categories, 0, 2, 4, 8 and 12 days after insemination) and their interaction.

220 We reported Cohen's d with their bootstrapped 95\% confidence intervals (Nakagawa

221 \& Cuthill 2007) as measures of effect size for the comparison between mean sperm

222 reserves before and after copulation (Garamszegi 2009). We reported standardised

223 slopes as a measure of effect size for the relationship between female body length

224 and fecundity (Schielzeth 2010). Non-parametric post-hoc comparisons after Kruskal-

225 Wallis' tests were performed using Conover's-test implemented in PMCMR packages

226 (Pohlert 2014). The tests were performed using $R 3.2 .5$ (R core team 2016) or JMP 22710.0 (SAS institute).

228

Results

Animal size and female fecundity

232 A total of 108 pairs ( $n=53$ before ejaculation, and $n=55$ after ejaculation) were 233 measured. Thirty-seven females were infected with $N$. granulosis, 23 were infected 234 with Dictyocoela, and 48 were uninfected (control). Body length did not differ as a 235 function of the female's parasitic status in either males $\left(F_{2,105}=0.43, p=0.65\right.$, 236 supplementary Fig. S1a) or females $\left(F_{1,106}=0.03, p=0.97\right.$, supplementary Fig. S1b). 237 There was no difference in body length between the two groups (before and after 238 ejaculation $)$ in males $\left(F_{1,106}=0.42, p=0.52\right.$, Cohen's $d=-0.13,95 \% \mathrm{Cl}=[-0.53$; 239 0.22], supplementary Fig. S1c) or in females $\left(F_{1,106}=0.18, p=0.68\right.$, Cohen's $d=$ $2400.08,95 \% \mathrm{Cl}=[-0.48 ; 0.30]$, supplementary Fig. S1d). The mean body size was 3.00 $241 \mathrm{~mm}(95 \% \mathrm{lC}=[2.94 ; 3.06])$ for males, and $2.70 \mathrm{~mm}(95 \% \mathrm{Cl}=[2.64 ; 2.75])$ for 
242 females. There was a significant positive relationship between female size and 243 fecundity $\left(F_{1,106}=22.3, p<10^{-5}\right.$, standardised slope $=0.42,95 \% \mathrm{Cl}=[0.24 ; 0.59]$,

244 Fig.1), but there was no effect of the parasitic status of the female $\left(F_{2,104}=0.18, p=\right.$ $2450.82)$ or the insemination status of the male $\left(F_{2,104}=0.0002, p=0.99\right)$ on female size.

Sperm reserves in males before and after insemination

248 There was no effect of male body size on sperm reserves before $\left(F_{1,51}=1.89, p=\right.$ $0.18)$ or after ejaculation $\left(F_{1,53}=0.68, p=0.41\right)$. Sperm reserves were significantly affected by the interaction between the insemination status and the parasitic status $\left(F_{2,104}=3.32, p=0.040\right.$, Fig.2A). The sperm count was significantly larger for males in amplexus (i.e. before copulation) than for males after copulation in each treatment 253 groups: $N$. granulosis infected females (Cohen's $d=1.37$ with $95 \% \mathrm{Cl}=[0.92 ; 1.95]$, $\left.254 \mathrm{~F}_{1,35}=17.14, \mathrm{p}=0.00021\right)$, Dictyocoela infected females (Cohen's $d=1.04$ with 95\% 255 $\left.\mathrm{Cl}=[0.39 ; 1.84], \mathrm{F}_{1,21}=6.07, \mathrm{p}=0.022\right)$ and uninfected females (control) (Cohen's $d$ $=2.78$ with $\left.95 \% \mathrm{Cl}=[2.029 ; 4.13], \mathrm{F}_{1,46}=92.078 \mathrm{p}<10^{-5}\right)$. Sperm reserves before ejaculation were significantly different among males, depending on the parasitic status of the female (Kruskal-Wallis test $\chi 2=6.7824, \mathrm{df}=2, \mathrm{p}=0.034$ ). Males paired with a female infected with $N$. granulosis (Conover's post-hoc test, $p=0.048$ ) or Dictyocoela $(p=0.016)$ had significantly lower sperm reserves than males from the control group. After ejaculation, sperm reserves were not significantly different among 262 males, whether paired with infected females or uninfected females (Kruskal-Wallis 263 test $\chi 2=1.77, \mathrm{df}=2, \mathrm{p}$-value $=0.41)$. The comparison of sperm investment as a

264 function of the parasitic status of females was based on the effect size (Cohen's d) of 265 the average difference in sperm count before and after ejaculation. For each 266 treatment, the value of the effect size was large (sensu Cohen 1988) but a direct 
267 comparison of the 95\% Cls (Cumming \& Finch 2005, Krzywinsk \& Altman 2013) 268 revealed a significantly larger sperm investment (twice larger) for the uninfected 269 group than for the two infected groups (Fig. 2B).

270 We estimated the average sperm number in the ejaculate as the difference between 271 the mean sperm reserves before and after ejaculation (+/-95\% confidence interval 272 based on 10000 bootstraps): $\mathrm{n}=532(95 \% \mathrm{Cl}=[415 ; 639])$ for the uninfected 273 females, $\mathrm{n}=383(95 \% \mathrm{Cl}=[212 ; 565])$ for females infected with $N$. granulosis, and $\mathrm{n}$ $274=234(95 \% \mathrm{Cl}=[49 ; 427])$ for females infected with Dictyocoela. Because we 275 counted the sperm number in $40 \mu \mathrm{L}$ among the $1000 \mu \mathrm{L}$ in which one testis was 276 dissected, we can estimate the total ejaculate size as $((532 \star 1000) / 40)^{\star} 2=26600$ 277 sperm for uninfected females $(\mathrm{Cl}=[20750 ; 31950]), 19150$ for females infected with 278 N. granulosis $(\mathrm{Cl}=[10600 ; 28250])$, and 11700 sperm for females infected with Dictyocoela $(\mathrm{Cl}=[2450 ; 21350])$.

280

Sperm replenishment

282

283 Sperm reserves increased significantly in males with time spent since copulation $284\left(F_{4,138}=47.19, \mathrm{P}<10^{-5}\right)$ but was not influenced by male size $\left(\mathrm{F}_{1,137}=2.36, \mathrm{P}=\right.$ 285 $0.140)$ nor by the interaction between male size and time since copulation $\left(F_{4,133}=\right.$ $0.767, P=0.548)$. Post hoc comparisons showed no difference in sperm reserves 287 between freshly-mated males and males two days after a copulation event (Fig. 3). 288 Eight and 12 days after a copulation event, males had more sperm than other males, without any significant difference between them (Fig. 3).

\section{Discussion}


We observed a negative effect of females' infection status on males paired with

293 them, in terms of both sperm reserves before ejaculation and ejaculate size. Indeed, 294 males paired with infected females had significantly lower initial sperm reserves than 295 males paired with uninfected females, whereas their final sperm reserves after 296 insemination did not differ, reflecting a lower number of sperm provided during 297 insemination. This could be explained by three non-exclusive hypotheses. First, 298 based on our screening of sperm replenishment dynamics, males paired with infected 299 females could be those that had less time to replenish their reserves between two copulations. Such a pattern could occur if infected females moulted more rapidly than 301 uninfected ones, which would reduce amplexus duration before copulation. 302 Alternatively, males paired with uninfected females could be in pair for longer prior 303 collection. However, since the dynamics of sperm replenishment is quite rapid 304 (around 8 days), this possible difference was not huge. If such a pairing pattern was 305 true, this would mean that males engaging pairing with uninfected females would be those able to monopolize females earlier.These hypotheses remain to be tested.

307 Second, when paired with infected females, males could strategically allocate less 308 energy in the production of gametes. As first argued by Dewsbury (1982), a single 309 male gamete may be cheap, but as males transfer large numbers of sperm, gamete production could be energetically expensive. Thus, males could modulate their 311 allocation in sperm production according to female quality by allocating less energy in 312 gamete production when paired with infected females (Reinhold, Kurtz \& Engqvist, 313 2002). Third, males paired with infected females could differ in competiveness or 314 body condition from males paired with uninfected females, as suggested by the fact 315 that unpaired males have generally lower sperm reserves than paired males 316 (Lemaître, Rigaud, Cornet \& Bollache 2009). Consistent with the major role of male- 
male competition for access to receptive females in gammarids (Ward \& Porter 1993, Dick \& Elwood 1996, Bollache \& Cézilly, 2004), it is possible that those in the best condition have a higher access to uninfected females. If males in poorer condition were less competitive and less efficient in finding or monopolising uninfected 321 females, they might have to accept the second-choice females remaining in the 322 population. Furthermore, the decision to enter into precopula might not solely be 323 under male control, and females could resist male attempts to grasp them 324 (Jormalainen \& Merilaita 1995, Jormalainen 1998). If uninfected females were more able to resist attempts from males than infected ones, only the most competitive and in best condition males would be able to pair with them.

327 Our results are consistent with previous observations in G. roeseli reporting that the 328 parasitic status of females does not appear to affect their fitness, neither in terms of 329 fecundity nor body length (Haine et al. 2004). This pattern is in contrast with the 330 situation in G. duebeni, where infection confers a fitness cost in terms of fecundity 331 (e.g. Dunn et al. 2006), and therefore, makes it difficult to invoke for G. roeseli the 332 adaptive strategic male sperm allocation based on differences in female fecundity 333 proposed in G. duebeni (Dunn et al. 2006). Differences in sperm reserves and ejaculate size may therefore result from differences in cues used by males to identify infected females. As precopulatory mate guarding is a long-lasting and intimate 336 interaction between the partners, we may propose that the male relies on behavioural 337 cues to assess whether its partner is a genuine female or a feminised male. Nosema 338 granulosis and Dictyocoela sp. have been shown to be sex ratio distorting parasites 339 in gammarids, reversing male hosts into phenotypic females (Terry et al. 2004; 340 Rodgers-Gray et al. 2004; Haine, Motreuil \& Rigaud 2007; Ironside \& Alexander 341 2015). A number of infected females are therefore genetic males reversed by 
parasites. In terrestrial isopod crustaceans infected with the feminising Wolbachia

343 bacteria, such 'false females' do not behave entirely as normal females during the 344 copulation sequence, resulting in higher rates of copulation failure and, in case of successful copulations, lower sperm investment in infected females compared to uninfected ones (Moreau, Bertin, Caubet \& Rigaud 2001, Rigaud \& Moreau 2004). Since mate recognition in crustaceans is based on contact pheromones present on 348 the cuticle (Caskey, Hasenstein \& Bauer 2009; Zhang et al. 2011), differences in cuticular compounds between infected and uninfected females may explain the observed pattern. Investigating the behaviour and cuticle compounds of infected vs. uninfected $G$. roeseli females during mate guarding would therefore be helpful to 352 further understand the sperm investment pattern observed in this study. Another 353 explanation, which does not involve a directional preference for uninfected female, could be that infected females show less resistance to pairing attempts (Jormalainen \& Merilaita 1995). Thus, only the most competitive males (with the largest reserves of sperm) could pair with more resistant uninfected females, the less competitive males only being able to pair with the less resistant infected females.

Gammarus roeseli males showed large sperm investment at each insemination event (between c.a. $50 \%$ and $75 \%$ of their sperm reserves constitute the ejaculate). Such a sperm depletion is consistent with the values reported in Gammarus pulex 361 (Lemaître, Rigaud, Cornet \& Bollache 2009), and confirms that the sperm investment 362 is substantial in Gammarus. However, as also noted by Lemaître, Rigaud, Cornet \& 363 Bollache (2009), sperm replenishment was achieved within less than a dozen days. 364 Initial sperm reserves in G. roeseli were double those in G. pulex: around 10 365 sperm $/ \mu \mathrm{L}$ in $G$. pulex before copulation, and less than 2.5 sperm/ $\mu \mathrm{L}$ after copulation, 366 while in $G$. roeseli they were around 22 sperm/ $\mu \mathrm{L}$ before copulation and more than 5 
sperm/ $\mu \mathrm{L}$ after copulation. As observed in terrestrial isopods (Moreau \& Rigaud 2003), we may propose that these higher sperm reserves could be due to a selection pressure induced by the excess of females in populations of $G$. roeseli (Haine et al. 2004).

Future studies should carefully assess the influence of parasites on male mate 372 choice and female behaviour in order to understand pairing processes leading to 373 these mating patterns, and the link between male sperm reserves and female 374 infection status.

\section{Acknowledgments}

378 This work was supported in part by the Agence Nationale de la Recherche (ANR), grant reference ANR-15-CE32-0006-01 (CytoSexDet).

\section{References}

Arundell, K.L., Wedell N., \& Dunn A.M. 2014. Perceived risk of sperm competition affects sperm investment in a mate-guarding amphipod. Animal Behaviour 87, 231-238.

Bandi, C., Dunn, A.M., Hurst, G.D.D. \& Rigaud, T. 2001. Inherited microorganisms, sex specific virulence and reproductive parasitism. Trends in Parasitology 17, 88-94.

Bollache, L. \& Cézilly, F. 2004. Sexual selection on male body size and assortative pairing in Gammarus pulex (Crustacea: Amphipoda): field surveys and laboratory experiments. Journal of Zoology 264, 135-141. 
Bollache, L., Rigaud, T. \& Cézilly, F. 2002. Effects of two acanthocephalan parasites on the fecundity and pairing status of female Gammarus pulex (Crustacea: Amphipoda). Journal of invertebrate pathology 79, 102-110.

Bouchon, D., Rigaud, T. \& Juchault, P. 1998 Evidence for widespread Wolbachia infection in isopod crustaceans: molecular identification and host feminization. Proceedings of the Royal Society B 265, 1081-1090.

Caskey, J.L., Hasenstein, K.H. \& Bauer, R.T. 2009. Studies on contact sex pheromones of the caridean shrimp Paldemonetes pugio: I. Cuticular hydrocarbons associated with mate recognition. Invertebrate Reproduction and Development 53, 93-103.

Charlat, S., Hurst, G.D.D. \& Mercot, H. 2003. Evolutionary consequences of Wolbachia infections. Trends in Genetics 19, 217-223.

Cohen, J. 1988. Statistical power analysis for the behavioral sciences, 2nd edition. Erlbaum, Hillsdale, NJ.

Cumming, G. and Finch, S. 2005. Inference by eye: Pictures of confidence intervals and thinking about levels of confidence. American Psychologist 60,170-180.

Dewsbury, D.A. 1982. Ejaculate cost and male choice. The American Naturalist 119, 601-610.

Dick, J.T.A. \& Elwood, R.W. 1996. Effects of natural variation in sex ratio and habitat structure on mate-guarding decisions in amphipods (Crustacea). Behaviour 133, 985-996.

Dunn, A.M., Andrews, T., Ingrey, H., Riley, J., \& Wedell, N. 2006. Strategic sperm allocation under parasitic sex-ratio distortion. Biology Letters 2, 78-80.

Edward, D.A. \& Chapman, T. 2011. The evolution and significance of male mate choice. Trends in Ecology and Evolution 26, 647-654. 
Figenschou L., Folstad, I., Rudolfsen, G., Hanssen, S.A., Kortet, R., Skau, Killie, J.E., Oskam, I.C., Strand, H. 2013. The relative effect of parasites and social status on sperm traits in Arctic Charr. Behavioral Ecology 24, 497-504.

Galipaud, M., Gauthey, Z. \& Bollache, L. 2011. Pairing success and sperm reserve of male Gammarus pulex infected by Cyathocephalus truncatus (Cestoda: Spathebothriidea). Parasitology 138, 1429-1435.

Galipaud, M., Bollache, L., Oughadou, A., \& Dechaume-Moncharmont, F.-X. 2015. Males do not always switch females when presented with a better reproductive option. Behavioral Ecology, 26, 359-366

Garamszegi, L. Z., Calhim, S., Dochtermann, N., Hegyi, G., Hurd, P.L., Jargensen, C., Kutsukake, N., Lajeunesse, M.J., Pollard, K.A., Schielzeth, H., Symonds, M.R.E., and Nakagawa, S. 2009. Changing philosophies and tools for statistical inferences in behavioral ecology. Behavioral Ecology 20, $1363-1375$.

Gismondi, E., Rigaud, T., Beisel, J.-N., Cossu-Leguille, C. 2012. Microsporidia parasites disrupt the responses to cadmium exposure in a gammarid. Environmental Pollution 160, 17-23.

Grabner, D.S., Weigand, A.M., Leese, F., Winking, C., Hering, D., Tollrian, R. \& Sures, B. 2015. Invaders, natives and their enemies: distribution patterns of amphipods and their microsporidian parasites in the Ruhr Metropolis, Germany. Parasite \& Vectors 8:419.

Grafen, A. \& Ridley, M. 1983. A model of mate guarding. Journal of Theoretical Biology 102, 549-567

Haine, E.R., Brondani, E., Hume, K.D., Perrot-Minnot, M.J., Gaillard, M. and Rigaud, T. 2004. Coexistence of three microsporidia parasites in populations of 
the freshwater amphipod Gammarus roeseli, evidence for vertical transmission and positive effect on reproduction. International Journal for Parasitology 34, 1137-1146.

Haine, E.R., Motreuil, S. \& Rigaud, T. 2007. Infection by a vertically-transmitted microsporidian parasite is associated with a female-biased sex ratio and survival advantage in the amphipod Gammarus roeseli. Parasitology 134, 1363-1367.

Haeussler, E., Schmera, D. \& Baur, B. 2014. Parasitic mites influence intra- and interpopulational variation in sperm length in a simultaneous hermaphrodite land snail (Gastropoda: Helicidae). Biological Journal of the Linnean Society 113, 1036-1046.

Hamilton, W.D. \& Zuk, M. 1982 Heritable true fitness and bright birds - a role for 453 parasites. Science 218, 384-387.

Ironside, J.E. \& Alexander, J. 2015. Microsporidian parasites feminise hosts without paramyxean co-infection: support for convergent evolution of parasitic feminization. International Journal for Parasitology 45, 427-433.

Jarrige A., Riemann D., Goubault M. \& Schmoll T. 2015. Strategic sperm allocation in response to perceived sperm competition risk in a lekking insect. Animal Behaviour 109, 81-87.

Jiggins, F.M., Hurst, G.D.D. \& Majerus, M.E.N. 2000. Sex-ratio-distorting Wolbachia causes sex-role reversal in its butterfly host. Proceedings of the Royal Society B 267, 69-73.

464

Jormalainen, V. 1998. Precopulatory mate guarding in crustaceans: male 465 competitive strategy and intersexual conflict. The Quarterly Review of Biology 73, 275-304. 
Jormalainen, V., \& Merilaita, S. 1995. Female resistance and duration of mateguarding in three aquatic peracarids (Crustacea). Behavioral Ecology and Sociobiology, 3, 43-48.

Kageyama, D., Nishimura, G., Hoshizaki, S. \& Ishikawa, Y. 2002 Feminizing Wolbachia in an insect, Ostrinia furnacalis (Lepidoptera: Crambidae) Heredity 88, 444-449.

Krzywinski, M. and Altman, N. 2013. Error bars. Nature Methods 10, 921-922.

Lemaître, J.F., Rigaud, T., Cornet, S. and Bollache, L. 2009. Sperm depletion, male mating behaviour and reproductive 'time-out' in Gammarus pulex (Crustacea, Amphipoda). Animal Behaviour 77, 49-54.

Moreau, J., Bertin, A., Caubet, Y. \& Rigaud, T. 2001. Sexual selection in an isopod with Wolbachia-induced sex reversal: males prefer real females. Journal of Evolutionary Biology 14, 388-394.

Moreau, J. \& Rigaud, T. 2003 Variable male potential rate of reproduction: high male mating capacity as an adaptation to parasite-induced excess of females? Proceedings of the Royal Society B 270, 1535-1540.

Nakagawa, S. and Cuthill, I.C. 2007. Effect size, confidence interval and statistical significance: a practical guide for biologists. Biological Reviews 82, 591-605.

Parker, G.A. 1974. Courtship persistence and female-guarding as male time investment strategies. Behaviour 48,157-184.

Pöckl, M. 1993. Reproductive potential and lifetime potential fecundity of the freshwater amphipods Gammarus fossarun and G. roeseli in Austrian streams and rivers. Freshwater Biology 30, 73-91.

Pohlert, T. 2014. The pairwise multiple comparison of mean ranks package (PMCMR). R package <URL: http://CRAN.R-project.org/package=PMCMR>. 
Poulin, R. 2007 Evolutionary ecology of parasites (2nd edn). Princeton, NJ: Princeton University Press.

Reinhold, K., Kurtz, J. \& Engqvist, L. 2002. Cryptic male choice: sperm allocation strategies when female quality varies. Journal of Evolutionary Biology 15, 201209.

Rodgers-Gray, T.P., Smith, J.E., Ashcroft, A.E., Isaac, R.E., \& Dunn, A.M. 2004. Mechanisms of parasite-induced sex reversal in Gammarus duebeni. International Journal for Parasitology 34, 747-753.

R core team. 2016. R: A language and environment for statistical computing. $\mathrm{R}$ Foundation for Statistical Computing, Vienna, Austria.

Rigaud, T. \& Moreau, M. 2004. A cost of Wolbachia-induced sex reversal and female-biased sex ratios: decrease in female fertility after sperm depletion in a terrestrial isopod. Proceedings of the Royal Society B 271, 1941-1946.

Schielzeth, H. 2010. Simple means to improve the interpretability of regression coefficients. Methods in Ecology and Evolution, 1, 103-113.

Stoffel, M.A., Nakagawa, S., \& Schielzeth, H. 2017. rptR: Repeatability estimation and variance decomposition by generalized linear mixed-effects models. Methods in Ecology and Evolution. https://doi.org/10.1111/2041-210x.12797

Sutcliffe, D. 1992. Reproduction in Gammarus (Crustacea: Amphipoda): basic reproductive processes. Freshwater Forum 2,102-128.

Terry, R.S., Smith, J.E. \& Dunn, A.M. 1998 Impact of a novel feminising microsporidian parasite on its crustacean host. Journal of Eukaryotic Microbiology 45, 497-501.

Terry, R.S., Smith, J.E., Sharpe, R.G., Rigaud, T., Littlewood, D.T.J., Ironside, J.E., Rollinson, D., Bouchon, D., MacNeil, C., Dick, J.T.A. et al. 2004. 
Widespread vertical transmission and associated host sex-ratio distortion within the eukaryotic phylum Microspora. Proceedings of the Royal Society B 271, 1783-1789.

Ward, P.I. \& Porter, A.H. 1993. The relative roles of habitat structure and male-male competition in the mating system of Gammarus pulex (Crustacea: Amphipoda): a simulation study. Animal Behaviour 45, 119-133.

Wedell, N., Gage, M.J.G. \& Parker, G.A. 2002. Sperm competition, male prudence and sperm limited females. Trends in Ecology and Evolution 17, 313-320.

Yan, G.Y. \& Stevens, L. 1995. Selection by parasites on components of fitness in

Zhang, D., Terschak, J.A., Harley, M.A., Lin, J.D., Hardege, J.D. 2011.

528 Simultaneously Hermaphroditic Shrimp Use Lipophilic Cuticular Hydrocarbons as

529 Contact Sex Pheromones. Plos one 6, e17720. 


\section{Caption for figure}

533

534 Fig. 1. Female fecundity as a function of female body size (estimated from the height 535 of the fourth coxal plate, in millimetres) and female parasitic status: uninfected 536 females, females infected with $N$. granulosis, females infected with Dictyocoela. The 537 regression line is given for each treatment group.

538

539 Fig. 2. (A) Mean sperm number (+/- 95\% confidence interval) as a function of the 540 male status (solid circle: before copulation, open circle: after copulation) and the 541 treatment group (the male is either paired with an uninfected female, a female 542 infected with N. granulosis, or a female infected with Dictyocoela). (B) Effect size of 543 the sperm investment (Cohen's d) with bootstrapped $95 \% \mathrm{Cl}$ as a function of the 544 treatment group. Different letters indicate statistically significant differences based on 545 comparison of the $95 \%$ Cls.

547 Figure 3. Mean sperm number (+/-95\% confidence interval) as a function of the time 548 since copulation. The first points correspond to the mean sperm number measured in 549 the testes a few hours after copulation. Different letters indicate statistically significant 550 differences (Tukey post-hoc comparisons). 
554 Fig. 1

555

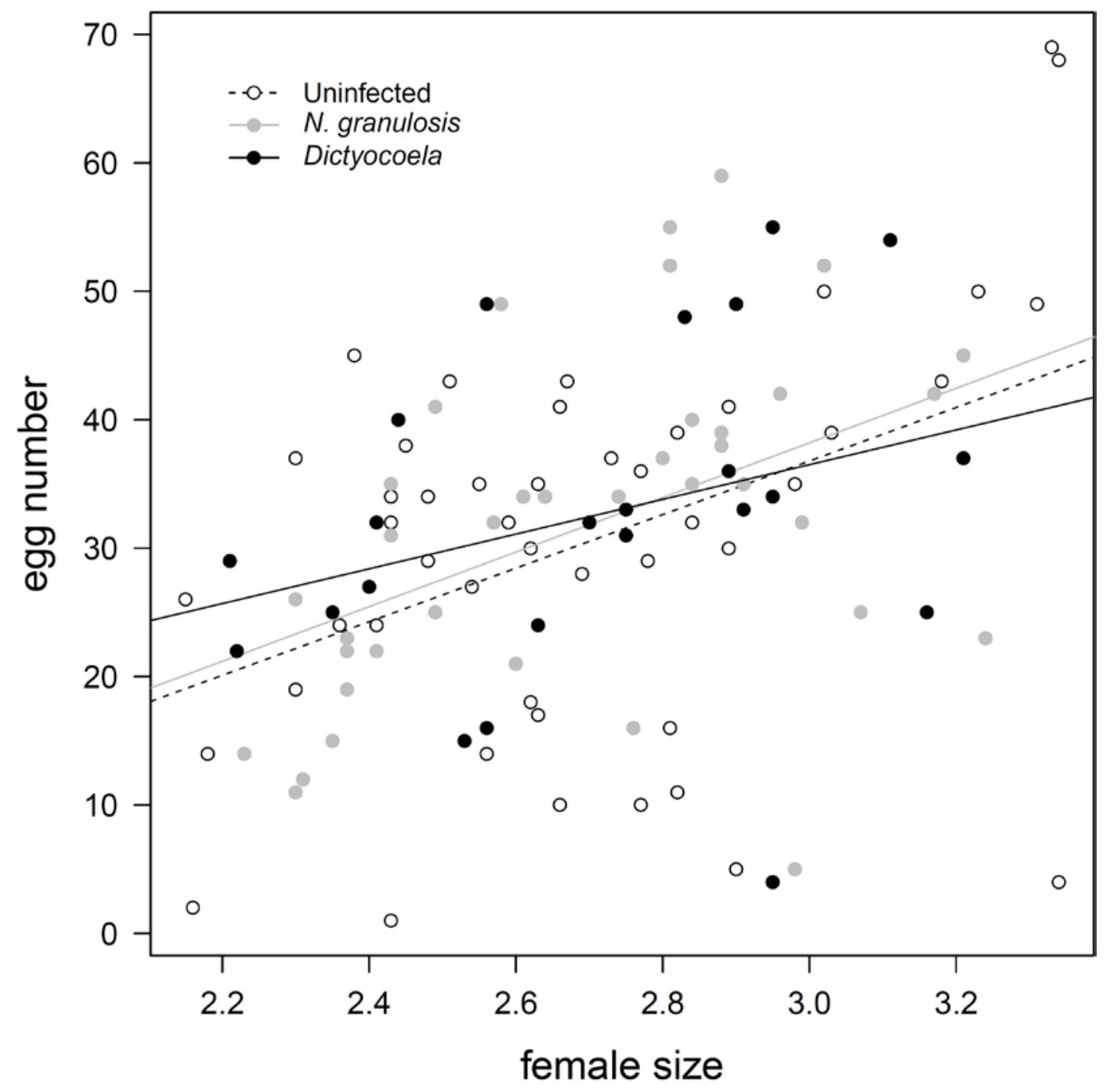

556

557 
Fig. 2
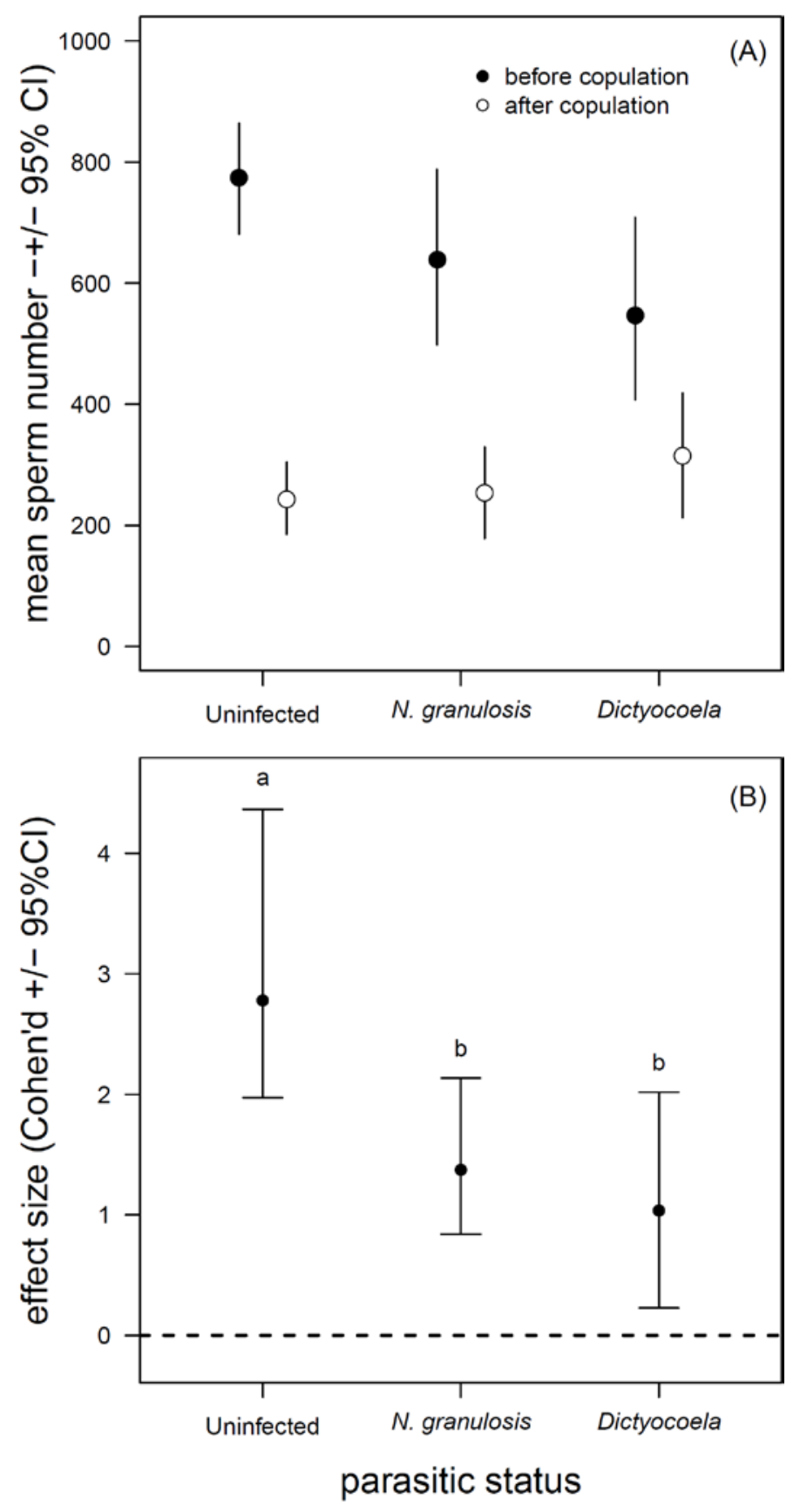

560

561

562 
Fig. 3

564

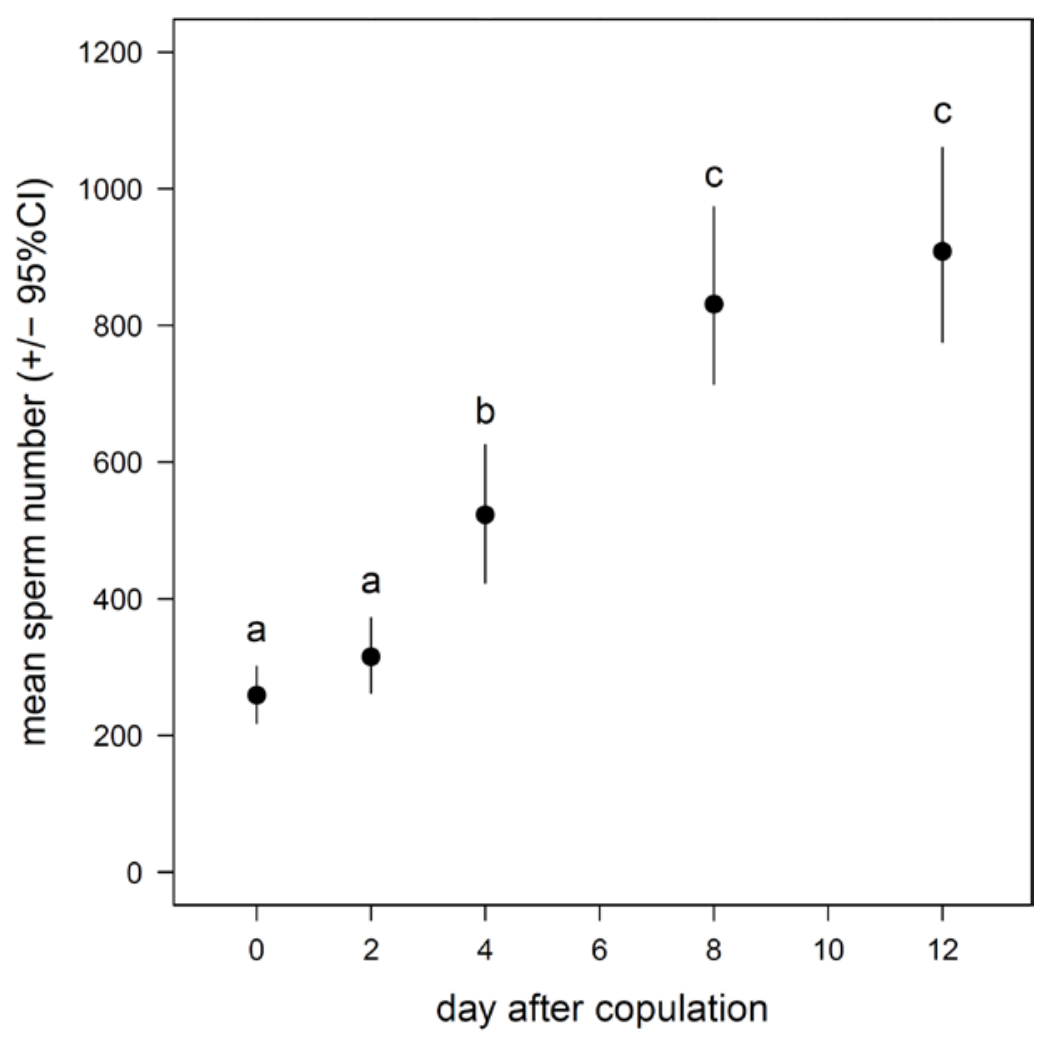

565

566

567 

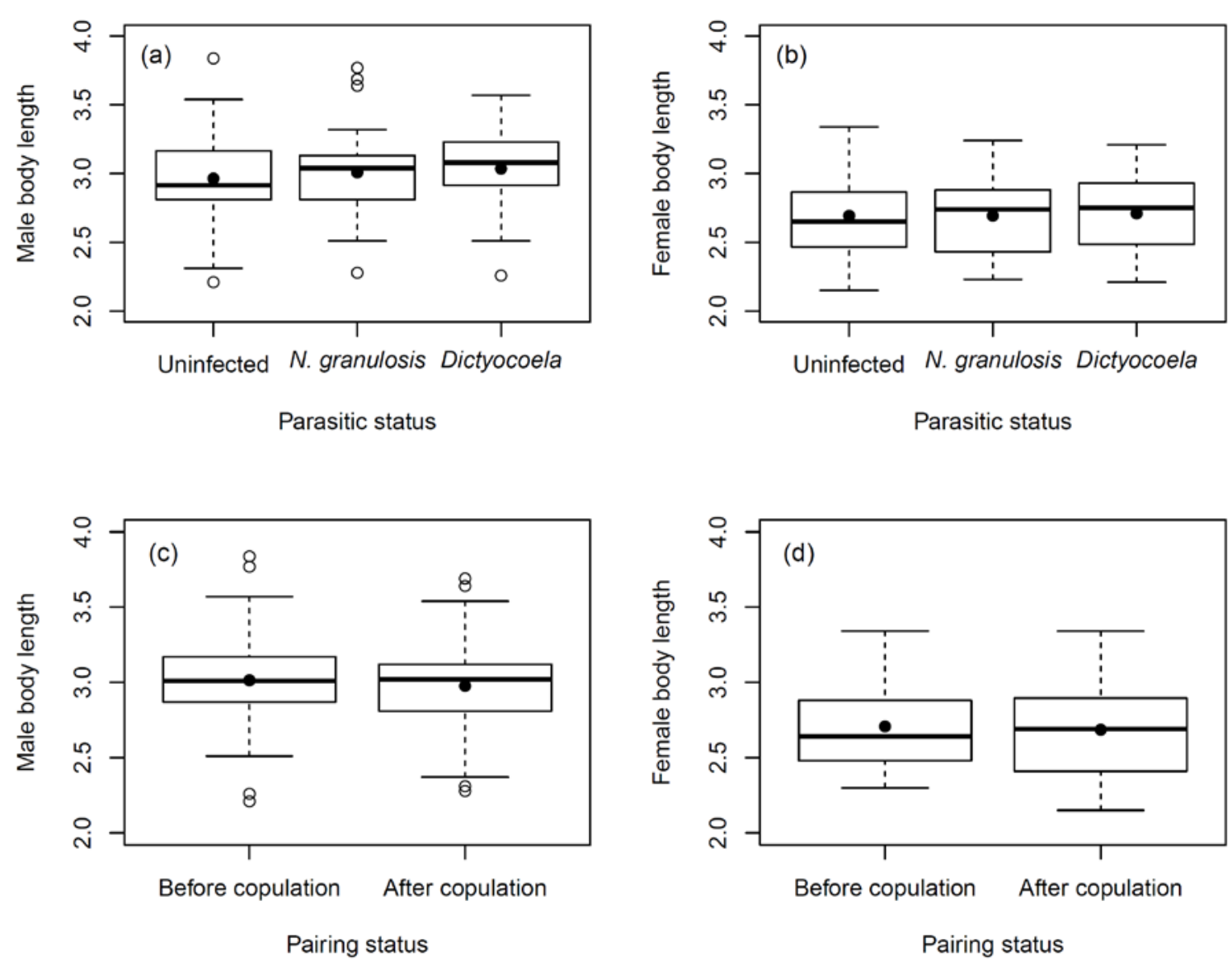

572

Fig S1. Boxplot of body length (estimated from the height of the fourth coxal plate, in

574 millimetres) as a function of treatment group (parasitic status of the female) for males

575 (a) and females (b), and as a function of pairing status (before or after copulation) for

576 males (c) and females (d). For each group, the box figures the interval interquartile 577 (IIQ), the dark line the median value, the solid circle the mean value, and the open 578 circles the outliers. 